\title{
Pengembangan Prototype Aplikasi Pendukung Penerbitan KJP
}

\section{(Prototype Development of Supporting Applications for KJP Issuance)}

\author{
Heri Satria $^{1}$, Danang Sutrisno ${ }^{2}$, Kursehi Falgenti ${ }^{3}$ \\ ${ }^{1,2,3}$ Fakultas Teknik Ilmu Komputer, Universitas Indrprasta PGRI Jakarta \\ Jl. Raya Tengah No. 80, Kel. Gedong, Kec. Pasar Rebo, Jakarta Timur 13760 \\ ${ }^{1}$ heri.satria71@yahoo.com \\ ${ }^{2}$ dngs 3674 @gmail.com \\ ${ }^{3}$ kursehi falgenti@unindra.ac.id
}

\begin{abstract}
Abstrak -- Penerbitan KJP menjadi beban tambahan bagi sekolah-sekolah di DKI Jakarta. Pekerjaan seleksi penerimaan KJP menjadi berat karena banyaknya pemohon, sedangkan sumberdaya manusia yang memiliki keahlian dalam mengolah data terbatas. Proses seleksi menemui banyak kendala diantaranya sering terjadi kesalahan dalam menginput data karena kurangnya ketelitian. Dalam mengantisipasi permasalahan tersebut, penerbitan KJP di sekolah memerlukan aplikasi pendukung untuk memperlancar penginputan data. Penelitian ini bertujuan membangun prototype aplikasi pendukung penerbitan KJP di sekolah-sekolah yang ada di wilayah DKI Jakarta. Data pendukung pembuatan prototype ini peroleh di dua sekolah, yaitu SMUN 80 Jakarta dan SMP Darrosta Jakarta. Metode yang digunakan dalam penelitian ini adalah System Development Life Cycles dengan model water fall. Hasil penelitian berupa Aplikasi Pendukung penerbitan KJP untuk memudahkan sekolah dalam mengolah data. Basis data penerima KJP diambil dari sistem DAPODIK. Pengajuan Penerima KJP tidak perlu langsung diinput secara online, untuk menghindari kesalahan input data operator cukup melakukan sinkronisasi data pada aplikasi pendukung dengan sistem KJP Online. Fitur sinkronisasi ini belum bisa dijalankan karena harus melalui ijin UPT Pusat Pelayanan Pendanaan Personal dan Operasional Pendidikan (P4OP) Dinas Pendidikan PEMDA DKI Jakarta.
\end{abstract}

Kata kunci - Penerbitan KJP, Aplikasi Pendukung, DAPODIK

Abstract- Issuance of KJP is an additional burden for schools in DKI Jakarta. KJP acceptance selection work is heavy because of the large number of applicants, while human resources who have expertise in processing data are limited. The selection process encountered many obstacles including frequent input errors due to lack of accuracy. In anticipating these problems, KJP issuance in schools requires supporting applications to facilitate data input. This study aims to build a prototype of supporting applications for KJP publishing in schools in the DKI Jakarta area. Supporting data for making this prototype were obtained in two schools, namely SMUN 80 Jakarta and SMP Darrosta Jakarta. The method used in this study is System Development Life Cycles with a waterfall model. The results of the study are Supporting Applications for KJP publishing to facilitate schools in processing data. The KJP recipient database is taken from the DAPODIK system. KJP Recipient Submissions do not need to be directly inputted online, to avoid operator data input errors, simply synchronize data to the supporting application with the KJP Online system. This synchronization feature cannot be implemented because it has to go through the UPT Pusat Pelayanan Pendanaan Personal dan Operasional Pendidikan (P4OP) Dinas Pendidikan PEMDA DKI Jakarta.

Keywords-KJP Publishing, supporting applications, DAPODIK.

\section{PENDAHULUAN}

Program Kartu Jakarta Pintar (KJP) merupakan bentuk upaya Pemerintah Provinsi DKI Jakarta dalam meningkatkan akses pendidikan yang berkualitas. Masyarakat yang tidak mampu dapat mewujudkan wajib belajar 12 tahun. KJP adalah program strategis untuk kalangan masyarakat yang tidak mampu mengenyam pendidikan minimal sampai dengan tamat SMA/SMAK, dengan dibiayai penuh dari dana APBD Provinsi DKI Jakarta. Hak warga untuk mendapatkan pendidikan dasar di DKI Jakarta dijamin dengan kartu KJP ini. Penerima KJP ini dijamin tepat sasaran oleh pemerintah DKI Jakarta melalui UPT Pusat Pelayanan 
Pendanaan Personal dan Operasional Pendidikan (P4OP), dengan menyusun delapan tahapan dalam penerbitan KJP. Tiga dari delapan tahapan dalam penerbitan KJP Yaitu; tahap pendataan siwa yang mendaftar, pengusulan dan merekapitulasi data siswa calon penerima KJP sesuai jenjang Pendidikan merupakan tanggungjawab kepala sekolah, hal tersebut menjadi beban tambahan pekerjaan tersendiri bagi sekolah.

Proses penerbitan KJP selama ini sudah didukung dengan sistem online (Gambar 1), tapi sistem ini hanya menerima data siswa yang sudah diseleksi oleh sekolah untuk mendapatkan bantuan. Dalam mendukung proses seleksi penerimaan beasiswa di sekolah tersebut diperlukan aplikasi pendukung. Beberapa penelitian tentang aplikasi pendukung dalam melakukan seleksi penerimaan beasiswa telah dilakukan, diantaranya: Rudiyanto [1] mengembangkan Sistem Penunjang Keputusan (SPK) penerima KJP di SMAN 84 Jakarta dalam bentuk aplikasi perangkat lunak menggunakan metode fuzzy Logic. Suryoko [2] Mengembangkan Sistem Penunjang Keputusan penerima KJP di SDN Negeri 01 Pagi Jakarta dengan Metode AHP. [3] menggunakan metode Simple Additive Wieghting (SAW) untuk menentukan siswa penerima KJP di Jakarta. Sistem Penunjang keputusan ini, dalam proses penentuan penerima KJP lebih objektif karena penerima KJP ditentukan berdasarkan kriteria-kriteria yang jelas dan sudah umum digunakan.

Sistem penunjang keputusan hanya membantu pihak sekolah dalam menentukan siswa-siswinya menerima KJP, kemudian pihak sekolah menginput data siswa calon penerima KJP melalui sistem online KJP. Proses selanjutnya dilakukan verifikasi melalui kunjungan kerumah siswa-siswi tersebut, hal ini menjadi beban para guru karena masih menggunakan cara manual yang belum didukung dengan sistem online, begitupun proses pengumpulan dokumen pendukung KJP masih dilakukan oleh operator sekolah. Pekerjaan seleksi penerimaan beasiswa menjadi berat karena banyaknya pemohon beasiswa namun sumberdaya manusia yang memilki keahlian dalam mengolah data terbatas, sehingga sering menemui kendala diantaranya kesalahan dalam menginput data, proses seleksi menjadi lama dan perlu ketelitian. [4]. UPT P4OP Dinas Pendidikan DKI Jakarta sebagai pihak yang terlibat langsung dalam penerbitan KJP menemukan banyak sekolah yang salah menginput data-data penting seperti Nomor NIK, tanggal lahir dan nama Ibu Kandung[5].
Program KJP banyak membantu siswa yang kurang mampu, namun dalam pelaksanaanya masih ditemukan kendala-kendala seperti: penyalahgunaan KJP, penerima KJP yang tidak sesuai sasaran dan lemahnya pengawasan dalam proses pelaksanaan penggunaan KJP [6]. Program KJP ini perlu terus didukung mengingat pentingnya pembiayaan pendidikan untuk peningakatan mutu pendidikan, ada korelasi yang positif antara besarnya biaya pendidikan terhadap peningkatan mutu pendidikan di Sekolah Dasar [7].

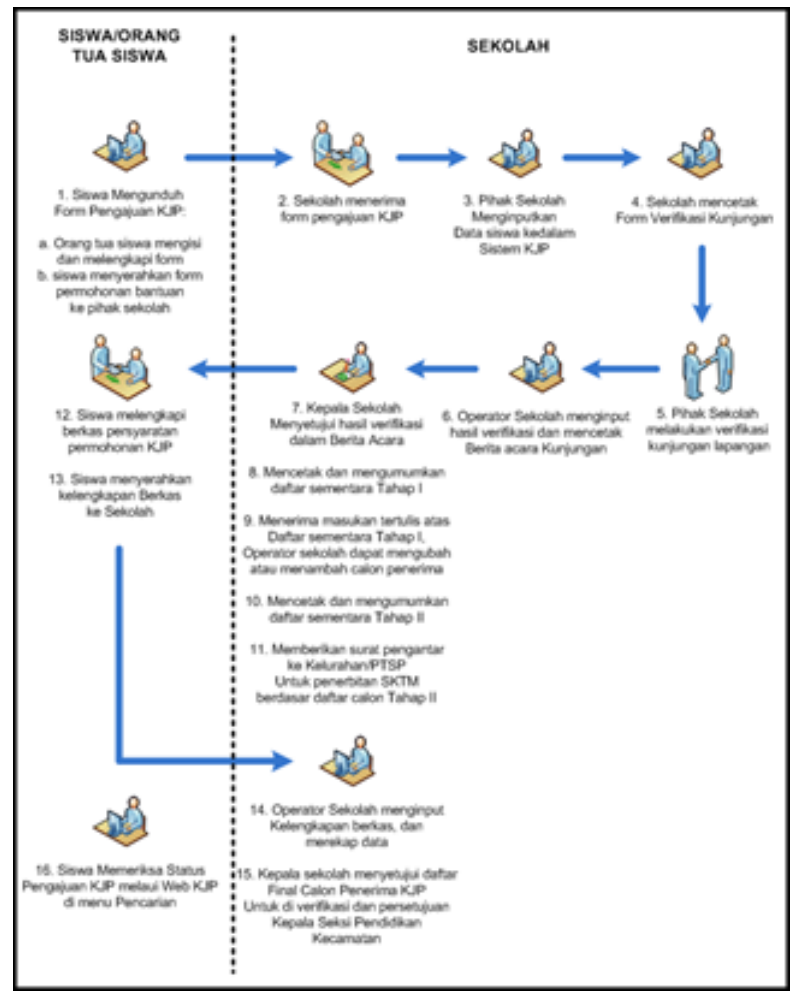

Gambar 1. Alur Kerja penerbitan KJP [8]

Pekerjaan administrasi di sekolah tidak hanya melakukan seleksi penerimaan KJP saja, pada awal tahun ajaran sekolah juga harus mengirimkan data siswa baru ke sistem DAPODIK. Dua pekerjaan ini membutuhkan input data ke sistem informasi yang berbeda. Idealnya sekolah memiliki aplikasi pendukung yang dapat memenuhi kebutuhan untuk input data DAPODIK dan untuk mendukung penerbitan KJP. Berbeda dengan sistem DAPODIK yang telah memiliki aplikasi pendukung, sisem KJP online tidak memiliki aplikasi pendukung untuk memverifikasi form pengajuan, Sistem KJP online hanya menerima data calon penerima KJP yang sudah diseleksi oleh sekolah. 


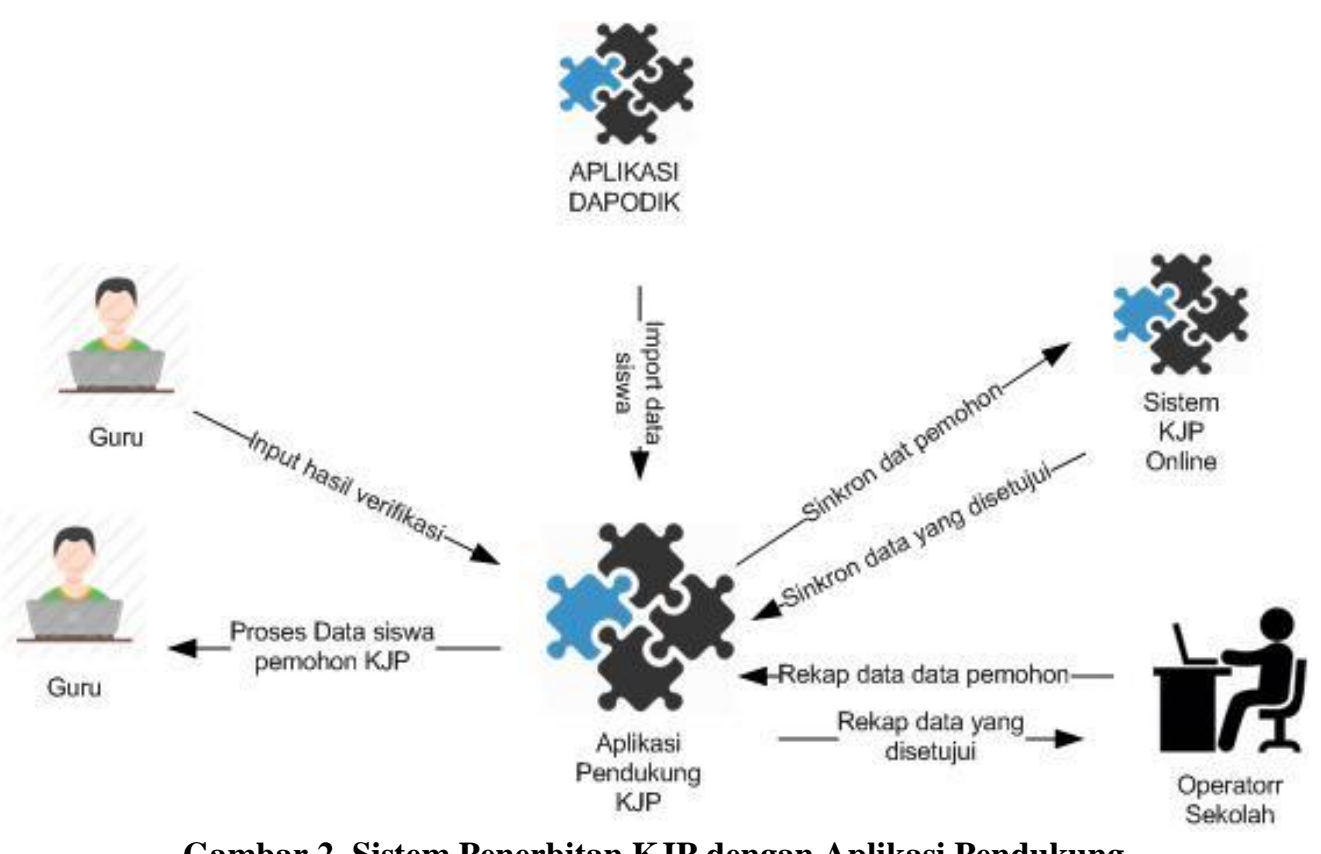

Gambar 2. Sistem Penerbitan KJP dengan Aplikasi Pendukung

Penelitian ini bertujuan merancang dan membangun aplikasi pendukung sederhana yang berfungsi sebagai basis data siswa bersumber dari sistem DAPODIK, basis data ini akan digunakan sebagai data profil siswa yang mengajukan permohonan untuk diseleksi oleh sekolah. Melalui aplikasi pendukung ini dapat mempermudah operator menyusun basis data siswa pemohon KJP, membantu operator merekap form pengajuan KJP dan data pendukung. Bagi guru aplikasi ini dapat membantu menjalankan proses mendata dan proses memverikasi form pengajuan KJP (Gambar 2).

Aplikasi ini diharapkan dapat disingkronkan dengan sistem KJP Online agar proses seleksi penerima KJP dapat berjalan dengan efektif dan efisian, menghindari kesalahan input, dan dapat mengurangi beban kerja guru dan tenaga administrasi. Fungsi aplikasi ini mirip dengan aplikasi pendukung Beban Kinerja Dosen (BKD) untuk pelaporan kinerja dosen. Kriteria manfaat dan kemudahan penggunaan Aplikasi BKD terbukti mempengruhi penggunaanya oleh para dosen [9], pengembangan aplikasi pendukung penerbitan KJP ini juga mempertimbangkan kriteria manfaat dan kemudahan dalam penggunaan. Dengan membangun aplikasi pendukung untuk para guru, maka perguruan tinggi juga ikut berperan aktif dalam mensukseskan program KJP di DKI Jakarta.

\section{METODE}

Penelitian yang akan dilakukan adalah riset dan development. Mengembangakan system KJP online yang sudah ada dengan membuat aplikasi pendukung untuk membantu sekolah dalam menerbitkan KJP. Metode pengembangan aplikasi menggunakan System Development Life Cycles dengan pendekatan pengembangan waterfall [10], proses pengembangan bertingkat. Studi lapangan mempelajari proses bisnis Penerbitan KJP di dua sekolah yaitu SMUN 80 Jakarta dan SMP Darrosta Jakarta. Melalui Analisa proses bisnis ini kemudian dilakukan perancangan dan pengembangan aplikasi penunjang penerbitan KJP. Aplikasi ini dirancang untuk dapat digunakan sebagai aplikasi standalone ataupun berjalan dengan arsitektur client-server, dimana database disimpan di server dan database ini dapat diakses oleh beberapa komputer client. Pembuatan aplikasi menggunakan bahasa pemograman delphi dan database menggunakan MySQL

\section{HASIL DAN PEMBAHASAN}

\section{A. Dekomposisi fungsi}

Pertama melakukan analisa kebutuhan aplikasi berdasarkan data yang dikumpulkan dari SMUN 80 Jakarta dan SMP Darrosta. Pada tahap analisa ini dibuat dekomposisi fungsi untuk mendapatkan big picture sistem yang akan dibangun (Gambar 3). Selanjutnya dibuat diagram kontek dan diagram nol, berupa rangkaian proses bisnis - penerbitan KJP di sekolah. Terdiri dari proses-proses, entitas, dan tabel di database yang saling terkait satu sama lain. 


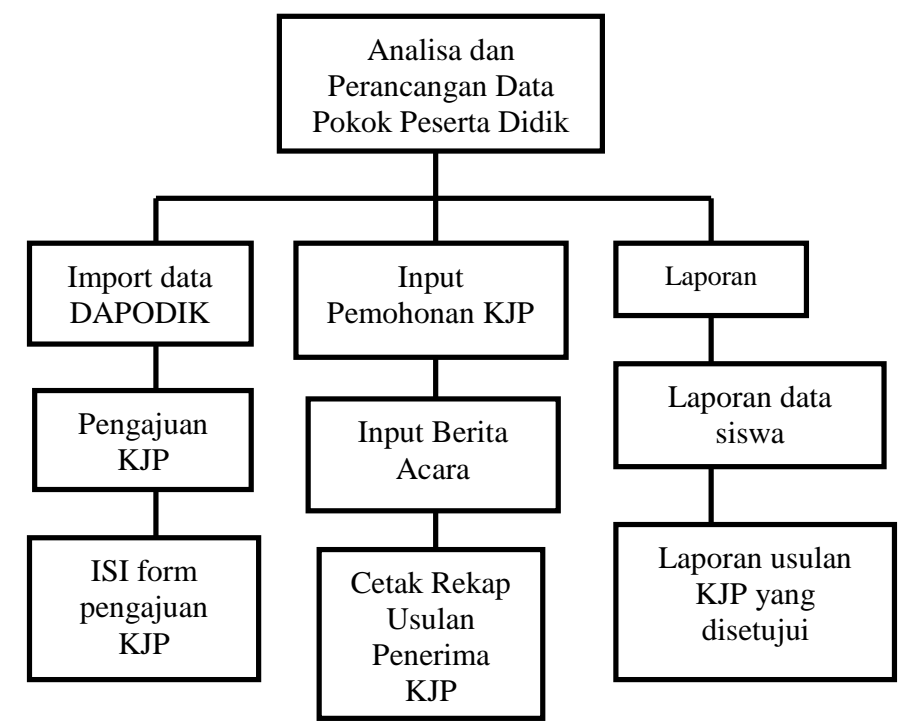

Gambar 3. Dekomposisi fungsi Sistem Informasi Penerbitan KJP

Pada diagram dekomposisi fungsi disusun beberapa fungsi dalam sistem informasi KJP. Fungsi-fungsifungsi ini yang akan mendukung proses penerbitan KJP di masing-masing sekolah.

\section{B. Diagram Konteks sistem informasi pendukung penerbitan KJP}

Diagram kontek menampilkan hubungan antara entitas dengan proses pada sistem untuk mendukung penerbitan KJP (Gambar 4). Dalam sistem pendukung penerbitan KJP ini hanya ada satu entitas (aktor) yaitu admin yang bertanggung jawab atas keseluruhan proses penerbitan KJP. Dalam pelaksanaannya admin ini bisa saja operator sekolah atau guru yang melakukan survey ke rumah-rumah siswa-siswinya.

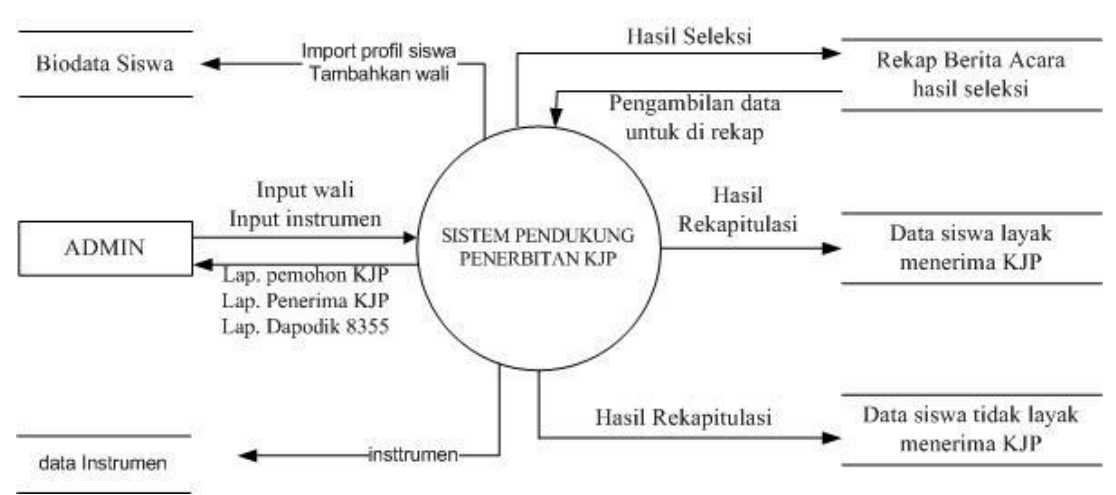

Gambar 4. Diagram kontek

\section{Diagram nol}

Pada diagram ini hubungan antara entitas admin dan proses-proses pada masing-masing tahapan penerbitan KJP lebih jelas terlihat (Gambar 5). Admin menginput data DAPODIK, setelah itu menginput data instrumen dari form KJP yang diisi oleh guru setelah kunjungan ke rumah siswa. Kemudin dilakukan proses seleksi oleh pihak sekolah berdasarkan kriteria-kriteria yang telah ditentukan oleh Dinas Pendidikan DKI Jakarta. Hasil proses seleksi ini diinput ke sistem pendukung KJP.

\section{Rancangan Database}

Basis data untuk aplikasi pendukung penerbitan KJP ini terdiri dari data-data siswa dan orangtua, data berita acara berupa instrumen yang diisi saat melakukan survey, data rekap siswa yang mengajukan KJP, dan rekap siswa yang menerima KJP (Gambar 6). Semua field pada tabel tidak semua ditulis pada rancangan ini karena pertimbangan ruangan yang tidak mencukupi. 


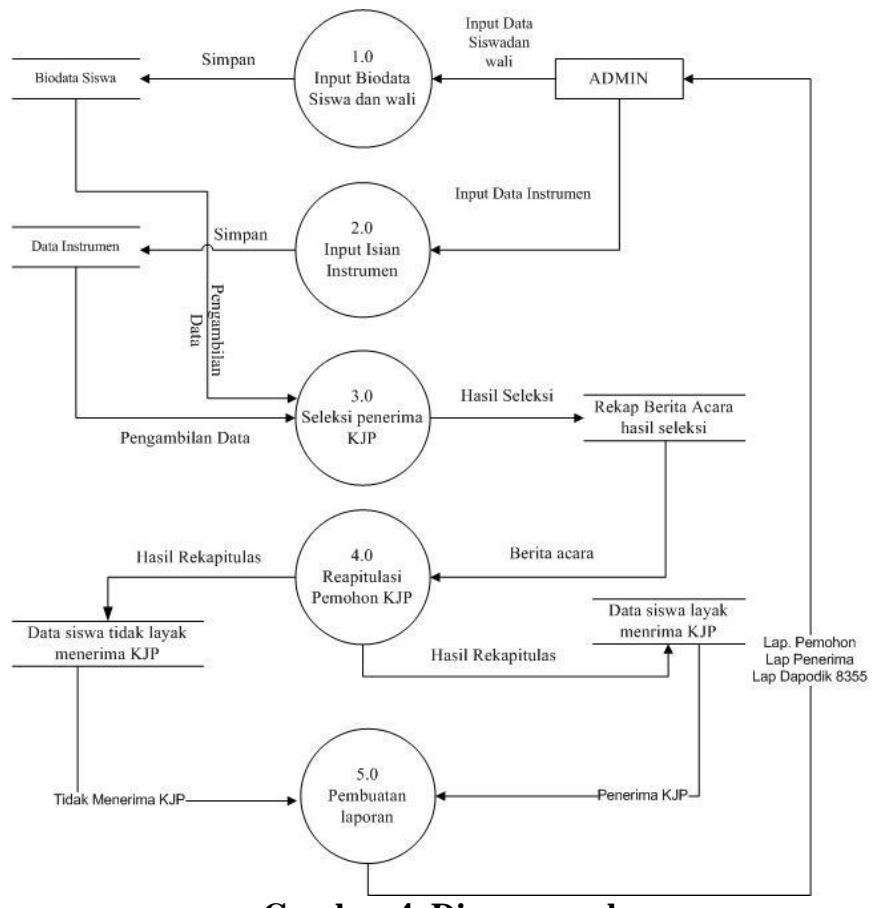

Gambar 4. Diagram nol

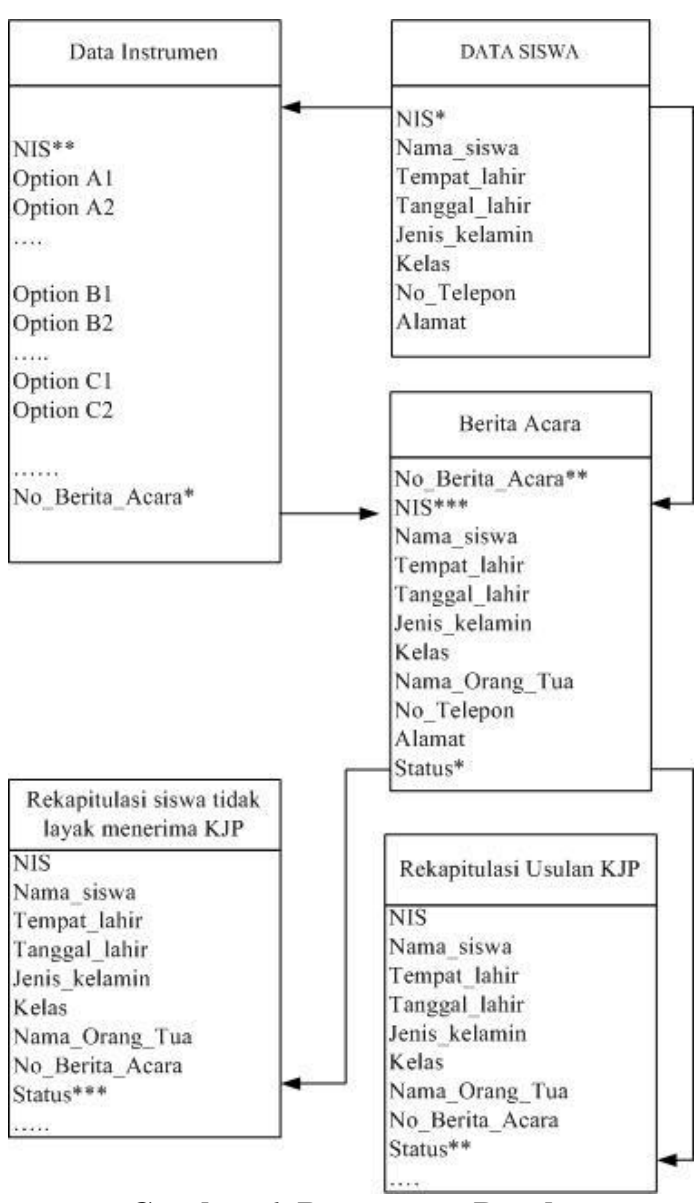

Gambar 6. Rancangan Database
E. ERD sistem yang diusulkan

Relasi data dapat dilihat pada Entity Reltion Diagram (Gambar 7)

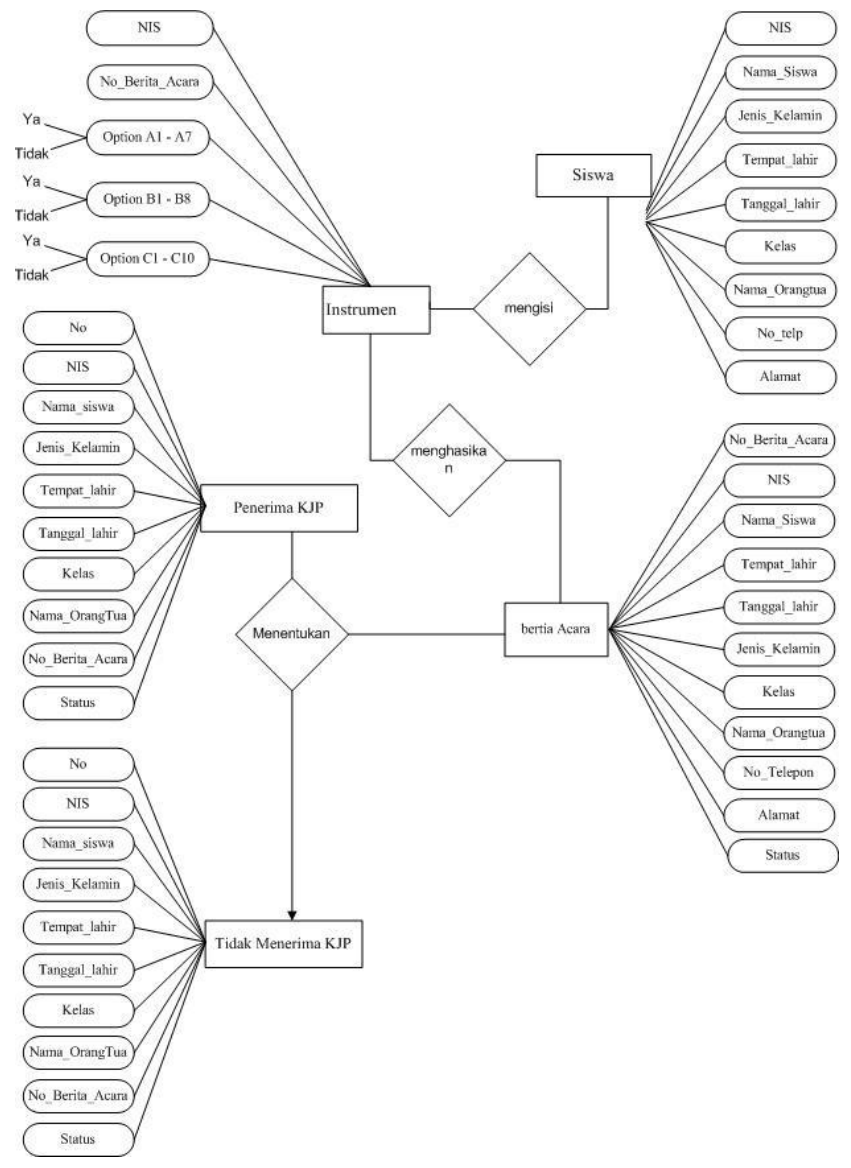

Gambar 7. ERD Aplikasi pedukung penerbitan KJP

F. Tampilan Program

Menu Utama

Kartu Jakarta Pintar

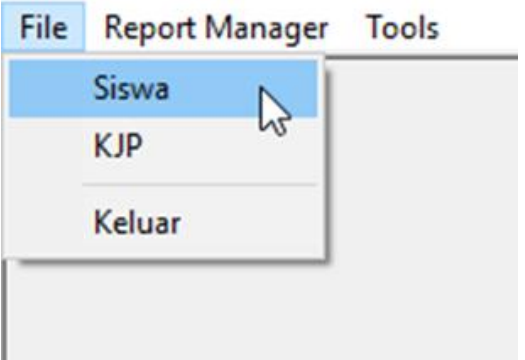

Gambar 8. Menu utama

Menu utama (Gambar 8) terdiri dari data siswa dan data KJP, laporan dan tools. Tool terdiri dari fungsi untuk import data DAPODiK dari Ms Excell. Pada Tool ini juga ada fungsi untuk sinkronisasi data dengan system KJP online, tapi fungsi ini belum diaktifkan. 


\section{G. Tampilan daftar Siswa}

Daftar siswa merupakan isian biodata siswa diperoleh dari Dapodik, data ini dimport ke aplikasi pendukung menggunakan Ms Excell (Gambar 9)

\begin{tabular}{|c|c|c|c|c|c|c|}
\hline \multicolumn{7}{|c|}{ (1) Daftar Siswa } \\
\hline Tambał & update & Hapus & Cetak & & & \\
\hline \multicolumn{2}{|c|}{ Pencarian } & I & & \multirow[t]{2}{*}{ NAMA SISWA } & $\checkmark$ & \\
\hline NIS & NISN & & ma Siswa & & \multicolumn{2}{|c|}{ Jenis Kelamin Nama Orang Tua } \\
\hline 478 & 31218612 & & II WAHTYDI & & Laki & SUHANDI \\
\hline 480 & 30933175 & & DIIAN AFRIANTO & & Lakj & Mulianto \\
\hline 481 & 25337669 & & RYAN PRATAMA & USUF & Laki & Murjani \\
\hline 482 & 25293282 & & IF KURNIAWAN & & Laki & SUKRAM \\
\hline 484 & 31672350 & & NUR HAFIFAH & & Perempuan & DJAHRUDIN \\
\hline 485 & 31672369 & & SAH AMALIA & & Perempuan & MIFTAH \\
\hline 486 & 25293231 & ALI & IYYAH SAUSAN AZ & ZAHRA & Perempuan & MISKUN \\
\hline 488 & 31672367 & AN & IGGELIA INTAN CA & HYANI & Perempuan & SOLIHIN \\
\hline 489 & 24716304 & AN & WARI ILHAM & & Laki & MANISO \\
\hline
\end{tabular}

Gambar 9. Daftar siswa

\section{H. Tampilan siswa yang mengisi formulir KJP}

Data siswa di eksport dari sistem DAPODIK ke Ms Excell, kemudian di import ke aplikasi pendukung KJP. Data yang mengisi formulir KJP dan mendownload dan mengisi formulir pendaftaran KJP dipisahkan dari data DAPODIK (Gambar 10)

\begin{tabular}{|c|c|c|c|}
\hline $\begin{array}{l}\text { O Kartu Jakarta Pintat } \\
\text { Ele Beport Manager Iools }\end{array}$ & & & \\
\hline \multicolumn{4}{|l|}{ O Daftar Pengajuan Kjp } \\
\hline Isi Formulir KJP Permoho & & Disetujui & \\
\hline Pencarian & & $\checkmark$ & \\
\hline No. Berkas NISN & NIS & Nama Siswa & Nama Orangtua \\
\hline DK00000057 30933175 & 480 & ADRIAN AFRIANTO & Mulianto \\
\hline DK0000005825337669 & 481 & ADRYAN PRATAMA YUSUF & Murjani \\
\hline DK0000006525293282 & 482 & AFIF KURNIAWAN & SUKRAM \\
\hline
\end{tabular}

\section{Gambar 10. List siswa}

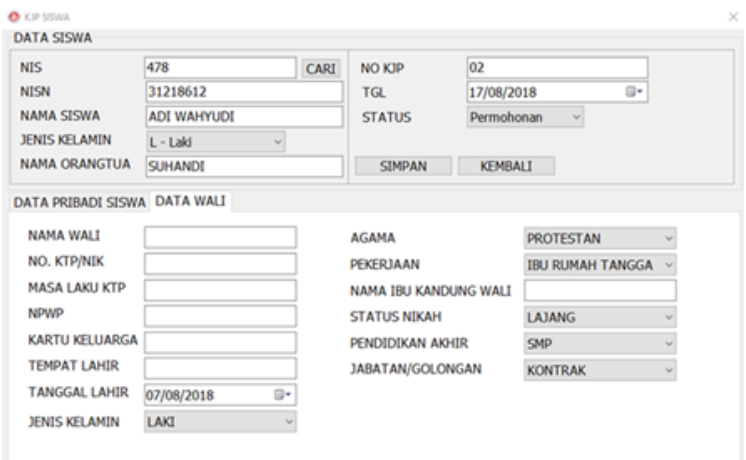

Gambar 11. Form isian data siswa dan wali

Data profil Siswa yang mengisi formulir pengajuan KJP ditambahkan sesuai format KJP, untuk itu perlu form isian wali yang tidak ada dalam data DAPODIK (Gambar 11). Data siswa yang mendaftar selanjutnya sudah terpisah dalam aplikasi pendukung penerbitan KJP. Statusnya ditetapkan sebagai pemohon KJP

\section{Tampilan form isian pemohonan KJP}

Setelah data profil dan kelengkapan administrasi terpenuhi, status siswa berubah menjadi pemohon KJP . Siswa tinggal menunggu untuk di survey oleh guru. Nomor dokumen merupakan nomor form instrumen yang harus dilengkapi guru sebagai dasar untuk menentukan status pengjuan KJP siswa (Gambar 12).

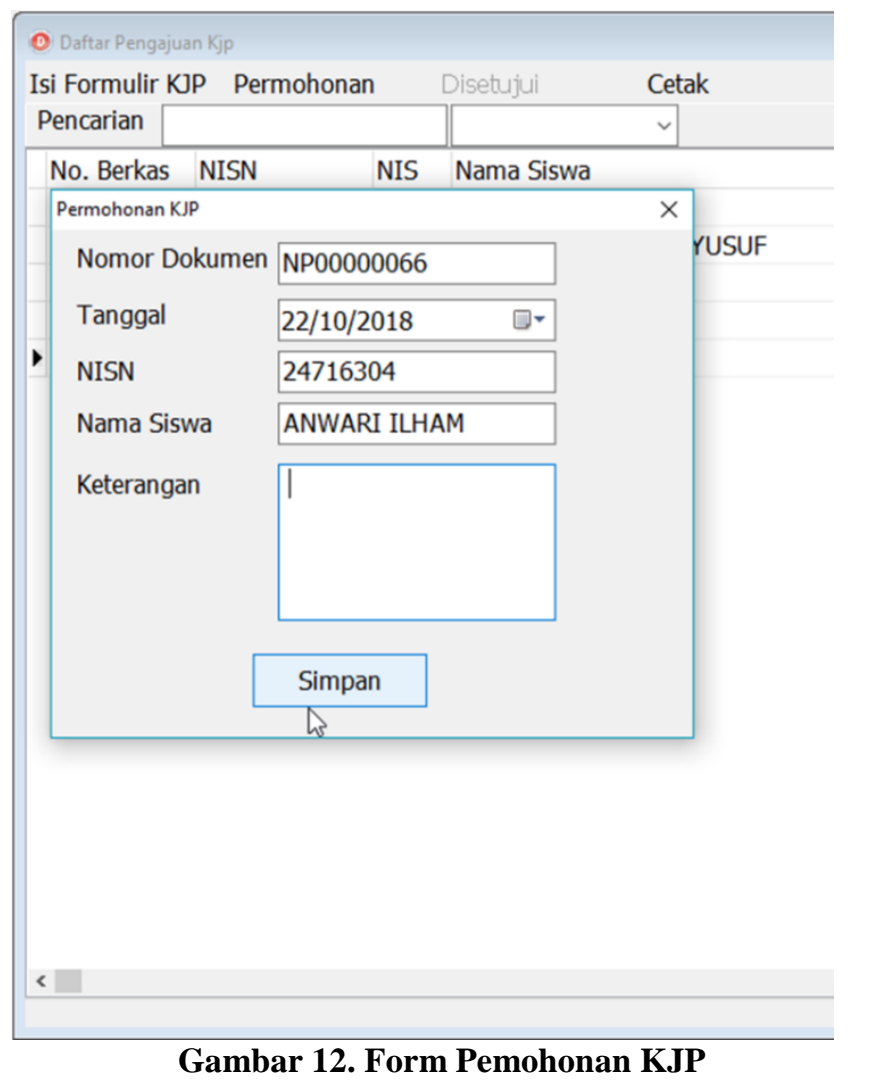

Setelah proses kunjungan guru ke rumah siswa selesai, pihak sekolah merekap hasil survey dan merekap seluruh pemohon KJP. Setelah proses rekap selesai biasanya sekolah mengirimkan data-data kelengkapan pemohon KJP melalui system KJP online. Aplikasi pendukung ini dirancang untuk dapat mensinkronkan data pemohon dengan database system KJP online, agar operator sekolah tidak perlu lagi mengisi data siswa pemohon KJP melalui system KJP online. Fungsi sinkron data ini belum bisa dijalankan karena belum ada kerja sama dengan UPT P4OP Dinas Pendidikan DKI Jakarta. 


\section{J. Form persetujuan KJP}

Form persetujuan KJP seharusnya juga disinkronkan dengan sistem KJP online. Selama ini siswa yang telah mengajukan, mengetahui namanya disetujui sebagai penerima KJP dari sistem online, sementara sekolah tidak mendapatkan data siswa yang menerima KJP. Sistem ini dirancang agar sekolah juga mengetahui siswa mereka yang mendapatkan KJP. Informasi siswa yang menerima KJP di sekolahnya di sistem KJP online dapat disinkronkan dengan aplikasi ini. Nomor rekening Bank DKI dijadikan sebagai primary key no KJP (Gambar 13).

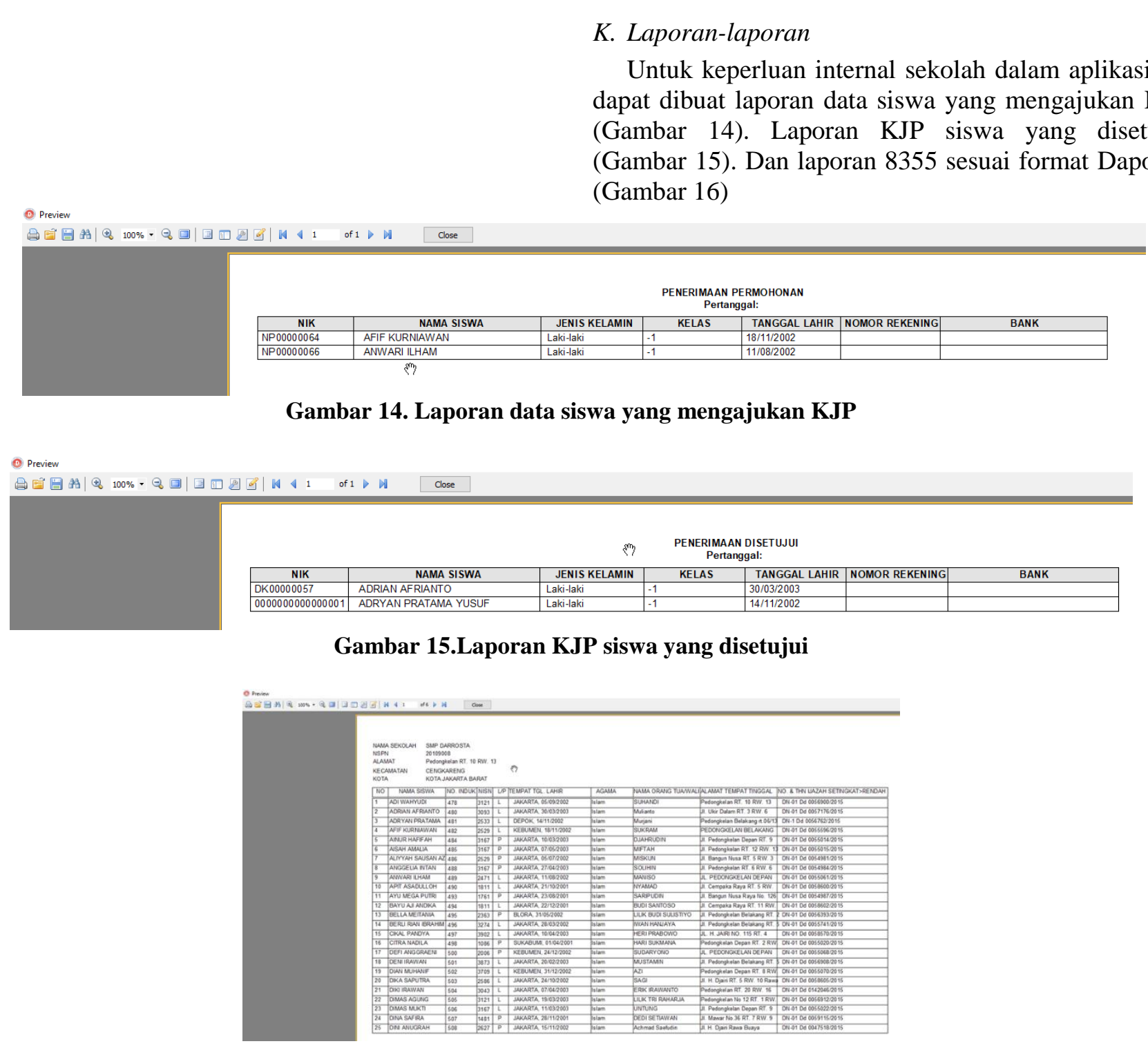

Gambar 16. Laporan Dapodik 8355

Gambar 14. Laporan data siswa yang mengajukan KJP

Gambar 15.Laporan KJP siswa yang disetujui

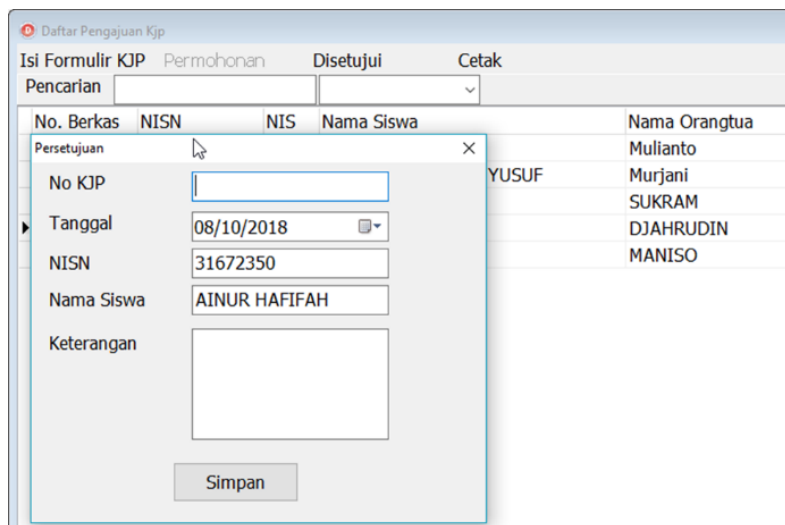

Gambar 13. Form Persetujuan Penerima KJP. apat dibuat laporan data siswa yang mengajukan KJP (Gambar 14). Laporan KJP siswa yang disetujui (Gambar 15). Dan laporan 8355 sesuai format Dapodik Gambar 16)
Dengan aplikasi pendukung penerbitan KJP ini, pekerjaan guru dan operator sekolah menjadi lebih ringan. Aplikasi ini dirancang sebagai aplikasi client server, yang dapat digunakan bersama-sama antara guru dan operator di sekolah. Guru hanya menginput hasil verifikasi kunjungan ke rumah siswa, dari hasil 
verifikasi ini operator dapat merekap jumlah siswa yang disetujui untuk di sinkronkan dengan system KJP Online. Dokumen pendukung sebagai syarat pengajuan KJP juga dapat diupload di aplikasi pendukung. Setelah semua berkas diupload operator dapat melakukan proses sinkronisasi. Selama ini upload dokumen pendukung langsung melalui sistem KJP online, proses ini memakan waktu cukup lama, karena dukumen diupload satu-satu. Dengan aplikasi pendukung seluruh dokumen dapat langsung diuploaad melalui proses sinkronisasi. Sayangnya fungsi ini belum dapat dijalankan karena harus mendapatkan ijin dari UPT P4OP Dinas Pendidikan DKI Jakarta.

\section{KESIMPULAN}

Sistem infromasi Pendukung penerbitan KJP yang dibuat bermanafaat bagi sekolah karena data DAPODIK juga terintegrasi dengan basis data di sistem informasi pendukung ini. Beberapa keuntungan yang didapatkan dengan adanya data Dapodik dalam sistem pendukung penerbitan KJP untuk sekolah adalah:

A. Operator sekolah lebih mudah melakukan proses seleksi siswa penerima KJP dengan terintegrasinya data Dapodik dengan sistem informasi pendukung.

B. Proses input data jadi berkurang, resiko kesalahan penginputan data juga jadi berkurang

C. Selain sebagai pendukung untuk penerbitan KJP operator juga dapat menggunakan data Dapodik untuk kegiatan internal seperti pembutan kartu peserta ujian

D. Dengan adanya basis data terintegrasi ini dapat juga membantu pihak sekolah bekerja lebih efisien dalam menlaksanakan proses penerbitan KJP.

Penlitian ini akan dilanjutkan, bekerja sama dengan UPT P4OP Dinas Pendidikan Pemda DKI Jakarta, untuk meminta ijin mendapatkan akses ke database sistem KJP online agar fungsi sinkronisasi tabel-tabel pada database dapat dilakukan.

\section{UCAPAN TERIMA KASIH}

Penelitian ini merupakan bagian dari luaran Hibah DIKTI Penelitian Dosen pemula tahun 2018.

\section{DAFTAR PUSTAKA}

[1] B. Rudianto, "Calon Penerima Kartu Jakarta Pintar Berbasis Decision Support System Di Sma Negeri 84," in Konferensi Nasional Ilmu Pengetahuan dan Teknologi, 2015, pp. 133-136.

[2] A. Saryoko, "Penentuan Penerima Kartu Jakarta Pintar Dengan Metode Analytical Hierarchy Process," Perspektif, vol. XV, no. 1, p. 10, 2017.

[3] E. Harli and M. Kom, Kajian Efektivitas Rencana Strategik Sistem Inforasi Kwartir Nasional Gerakan Pramuka mneggunakan AHP. 2013.

[4] D. Sulistyo and W. Sri, "PEMANFATAN INFORMASI TEKNOLOGI DALAM PENENTUAN BEASISWA SISWA KURANG MAMPU," J. Inform., vol. 9, no. 1, pp. 965-974, 2015.

[5] H. R. Aryani, "Evaluasi Program Kartu Jakarta Pintar di UPT P6o Dinas Pendidikan Provinsi DKI Jakarta," in Festval Riset Manajemen Ilmiah dan Akuntansi, 2006, pp. 609-615.

[6] Sukriyandi, "EFEKTIVITAS PROGRAM KARTU JAKARTA PINTAR ATAS DAN KEJURUAN ( Studi Kasus di Kecamatan Kebon Jeruk )," FAKULTAS ILMU SOSIAL DAN ILMU POLITIK UNIVERSITAS SULTAN AGENG TIRTAYASA, SERANG, 2017.

[7] N. Fattah, "Pembiayaan Pendidikan: Landasan Teori dan Studi Empiris," J. Pendidik. Dasar, vol. 9, no. April, 2008.

[8] PEMDA DKI, "Tentang Kartu Jakarta PIntar," 2005. [Online]. Available: www.kjp.jakarta.go.id.

[9] D. Yuniarto, "Analisis Penerimaan Penggunaan Aplikasi Laporan Beban Kerja Dosen Dan Evaluasi Pelaksanaan Tridharma Perguruan Tinggi Secara Online Menggunakan Technology Acceptance Model (TAM) (Studi Kasus Di Lingkungan Perguruan Tinggi Sebelas April Dan STMIK Sumedang)," Infoman's, vol. 12, no. $1,2018$.

[10] J. HM, Analisis dan Desain ( Sistem Informasi Pendekatan Terstruktur Teori dan Praktek Aplikasi Bisnis ). Yogyakarta: ANDI, 2017. 